\title{
Strengths Based Practice with Children with a Mental Health Condition
}

\author{
Abul Khan ${ }^{1,2, *}$, Abraham Francis ${ }^{3}$ \\ ${ }^{1}$ Child and Adolescent Psychosocial Therapist, Melbourne, Australia \\ ${ }^{2}$ James Cook University, Australia \\ ${ }^{3}$ Senior Lecturer, College of Arts, Society and Education, Division of Topical Environments and Societies, \\ James Cook University, Australia \\ *Corresponding Author: abul.khan@my.jcu.edu.au
}

\begin{abstract}
Children and young people attending mental health service deserve their treatment to build on their existing potentialities while reconstructing their protective factors and natural resilience. However, in the current bio psychosocial treatment system, under increasing domination of medical model, children's natural resilience and social environmental factors often do not get appropriate priority. Because of this trend, children's struggles with mental illness become prolonged amidst frequent presentation into the emergency department with several other risks. The paper has approached the idea of strength-based practice (SBP) as a respectful recognition to children's inherent capabilities to address and resolve their social and emotional difficulties in a safe and supportive environment. The construct of SBP has been discussed with the help of a case study alongside other literature.
\end{abstract}

Keywords Strength Based, Bio-psychosocial, Mental Health Condition, Partnership, Therapeutic Journey

\section{Introduction}

This paper is based on authors' experiences and reflections of working with children with mental illness for a period of 10 years in UK and Australia. The authors observed that children and young people attending Child and Adolescent Mental Health Service (CAMHS) services often returns to the services on multiple occasions over a period of time (Harpaz-Rotem, Leslie and Rosenbeck, 2004) for a number of factors: unresolved developmental trauma and attachment, poor support from family, limited insight and informed strategies to manage mental health needs, complex changes in the family and lack of support networks. These factors may be characterized as components that create natural resilience, which is essentially, as the core values of strength-based perspective. Every child and every family has their own resources, assets and potentialities which are detected, nurtured and regenerated in SBP (Laursen, 2000).
However, there are concerns on increasing dominance of medical model (Santrock, 2007; Yip, 2004) backed by the Diagnostic and Statistical Manual(DSM), the natural resilient factors often do not get appropriate values and convincing recognition, instead, pharmacological treatment gets priority. There are convincing research based evidences that drug therapy must be backed by psychosocial treatment (Beyond Blue, 2011; Council Of Australian Governments (COAG), 2012). In fact, there is clear national policy in Australia to explore empowering the natural psychosocial protective factors before considering drug therapy treatment (Beyond Blue, 2011; COAG (2012). In the absence of opportunities for building on natural resilience factors, the children bear significant risks of relapse and eventually re-enter into the mental health service.

This paper is focusing on the need to recognize and enhance the natural resilience factor through strength based approach for better outcome in CAMHS. We have used bullet points in different areas of this paper to make our thoughts straight, which the readers can easily comprehend without the effort of reading extensive paragraph. The paper has been constructed with appropriate literature reviews to set the scene followed by a case study to reflect the practical process of strength based practice before elucidating policy implications and need for future research.

\section{Children with Mental Health Condition}

Children and young people attending mental health services often suffer from anxiety, depression, emotional deregulations, post-traumatic stress, self-harm, suicidal ideations, eating disorder, sexual concerns and dissociative symptoms. These mental health issues are generally attributed to developmental adversities (abuse, neglect and trauma) and social environmental factors, physical environmental factors and genetic factors (Office of the High Commissioner for Human Rights (OHCHR), 2007, Shooter, 2008). The needy children are often anxious, confused and highly stressed leading to highly disorganized, distressful 
behavior and risky coping mechanisms like self-harm, substance misuse, suicidal ideation. In the context of human rights, these children are victims of their circumstances and must be treated with respect and dignity and have their voice heard in the decisions and interventions that affect their lives (Shooter, 2008).

In Australia, more young people die from suicides each year than road accidents, making suicide the leading cause of death among the young people (Beyond blue, 2013). According to a national survey, around 7.3 million or $45 \%$ of Australians aged 16-85 will experience some form of mental health-related condition such as anxiety, depression and drug misuse disorder in their lifetime (Australian Institute of Health and Welfare (AIHW, 2007). The AIHW statistics also reports that the government spend over 6 billion dollar per year to deal with mental health related issues. The grim picture has been further noted in 2011-2012, when there has been a steady decrease in high/very high levels of psychological distress experienced across most age groups (Australian Bureau of Statistics, 2013).

Although, there is no clear research on the specific area about reasons of multiple representations in CAMHS service, the authors have pragmatic experiences of observing the trend in Queensland, South Australia and Victoria, in Australia. Objective analysis of premature case closure through dropout brings some connection with the potentiality for revisiting the service. Research in the United States suggests that of $31-78 \%$ of children and young people with a psychiatric diagnosis bear risk of drop out of treatment prematurely (Oruche, Downs, Holloway, Drucker \& Aalsma, 2013; Burns, Costello \& Angold, 1995; Leaf et al, 1996). Wang (2007) completed a study on flow of servicers in child and adolescent mental health services in Canada and observed a dropout rate was $22.7 \%$ in those who were treated by psychiatrists and $21.9 \%$ in participants who were attended by psychologists.

\section{CAMHS and the Need for SBP}

The concept and structure of Child and Adolescent Mental Health Service (CAMHS) was outlined in the United Kingdom National Health Service report Together We Stand (Lavis, 2008). In the United Kingdom, CAMHS features in tier three of a 4-tiered multidisciplinary health care system:

- Tier 1: Universal Health Services provided by GPs, Nurses (Health Visitors), specialist family support agencies, schools and NGOs.

- $\quad$ Tier 2: Services offered by professionals working in the primary care system such as pediatricians, educational psychologists, and primary mental health workers.

- $\quad$ Tier 3: Specialised multidisciplinary teams including disciplines such as psychiatry, nursing, social work, psychology, physiotherapy, speech pathology and occupational therapy, working in the community
- $\quad$ Tier 4: Specialised teams functioning in inpatient/secure unit with clients with severe complex mental health needs.

However, the primary author has noticed some terminological changes in the implementation of the British model in Queensland and Victoria this is called Child and Youth Mental Health Service (CAMHS) with future plan to restructure it as child and young adult service by expanding the age group up to 25 years. This plan may be justified to manage systemic resource scarcity, however, the strategy raise fundamental questions of effectiveness and sustainability to manage the vast areas (age range 0-25) without careful planning on infrastructure and resource investment. The current CAMHS system has been struggling with resource scarcity in terms of infrastructure, staff shortage and staff training and development allocation (Khan, 2011). For example, in rural location where children with crisis presentation are often accommodated into inpatient adult unit, assessed and case managed by psychiatrists and clinicians in the adult community mental health services. This resource issue is a grey area in CAMHS system needs more objective study and policy decision and resource management.

In practice context, CAMHS assessment and intervention generally progress from bio-psychosocial perspectives that inform mental state examination, clinical risk formulations, intervention and recovery plans, discharge plan and then case closure (State of Victoria, 2006). The system also demands a robust co-ordination and communications among the CAMHS professionals and dedicated partnerships with other stakeholders and consumers including parents and carers. A comprehensive bio-psychosocial model refers to biological (medical, physical, genetic) psychological (thoughts, emotions, and behaviours), and social factors (practical issues, support networks, family connections \& environmental issues) which all play a significant role in a child's social and emotional functioning in the context of their disease or illness. Indeed, health is best understood in terms of a combination of these factors rather than purely in biological terms (Santrock, 2007). This is in contrast to the traditional, reductionist model of medicine that suggests every disease process can be explained in terms of an underlying deviation from normal function such as a pathogen, a genetic or developmental abnormality, or an injury (Engel, 1977). The bio-psychosocial perspective in contrast requires a comprehensive assessment of mental illness in an environment, which is therapeutically focused and evidenced by multidisciplinary professionals.

However, the bio psychosocial perspective, even though an established multidisciplinary method of CAMHS intervention, is often hijacked by the medical model because the medical professionals (i.e. Psychiatrist) are most often awarded the leadership position (i.e. clinical lead or Clinical Director) in clinical assessments and reviews (Pilgrim, 2002). This creates hierarchal imbalance and discrimination regarding credible representation of other disciplines. The 
other issue is poor social awareness about the unique contribution of psycho-social therapy leads to increasing reliance on medical input. For example, it has been often observed that the parents and carers of children with Attention Deficit Hyperactivity Disorder (ADHD) type symptoms, express strong preferences for medical intervention rather than exploring potential causes (e.g., alternative parenting strategies, behaviour management programmes and support network issues) or alternative treatment routes like individual and family therapy (Sayal, 2008). This approach of seeking quick solutions to manage the distressful behaviour of children is often counterproductive in terms of strengthening natural resilience outcomes. Pilgrim (2002) has stated that despite scientific and ethical virtues, the bio psychosocial model has not been properly realised, as is evidenced in the CAMHS system. Pilgrim expressed concern that this model seems to have been pushed into the shadows by a return to medicine and the re-ascendancy of a biomedical model.

In policy context, the World Health Organization has noted significant concerns that in spite of widespread recognition that psychosocial well-being and optimal development is a prerequisite for healthy, cohesive and productive societies, childhood mental and neurodevelopmental disorders have been widely neglected by policy makers and public health experts (World Health Organization (WHO), 2013). The UN Convention on the Rights of Child (OHCHR, 2007) states in Article, 39 outlines: States Parties shall take all appropriate measures to promote physical and psychological recovery and social reintegration of a child victim of: any form of neglect, exploitation, or abuse; torture or any other form of cruel, inhuman or degrading treatment or punishment; or armed conflicts. Such recovery and reintegration shall take place in an environment, which fosters the health, self-respect and dignity of the child (OHCHR, 2007). We could see the reflection of this in the WHO documentation as well. WHO has developed a mental health care tool kits for assessing and improving quality and human rights in mental health and social care (WHO, 2013a):
- living conditions to be safe and hygienic and the social environment to be conducive to recovery;

- the provision of evidence-based care for their mental and physical health condition, on the basis of free and informed consent;

- gearing services towards enhancing people's autonomy enabling them to engage in their own recovery plans;

- reporting and halting all inhuman treatment; and

- linking health services with employment, education, social and housing services in order to promote independent living in the community for mental health service users.

Objective understanding of the international policy mandates clearly reiterates empowerment based approach by strengthening the client and it's environment.

Here in Australia, The National Mental Health Strategy and the COAG (2012) National Action Plan on Mental Health has been structured for improving the provision of mental health services in Australia. The Fourth National Mental Health Plan promotes an integrated, whole- of government response to the improvement of mental health outcomes over the period 2009-2014, with five priority areas:

- social inclusion and recovery

- prevention and early intervention

- service access, coordination and continuity of care

- quality improvement and innovation

- accountability-measuring and reporting progress.

Governments committed to reporting progress annually to COAG in accordance with 25 indicators included in the plan.

The Road Maps for National Mental Health Reform2012-2022 is a comprehensive national strategy documents with a vision to promote good mental health outcome in Australia. It is interesting that the pathway strategy has been designed by using different social determinants of health framework in recognizing the wider factors in individual's mental health.

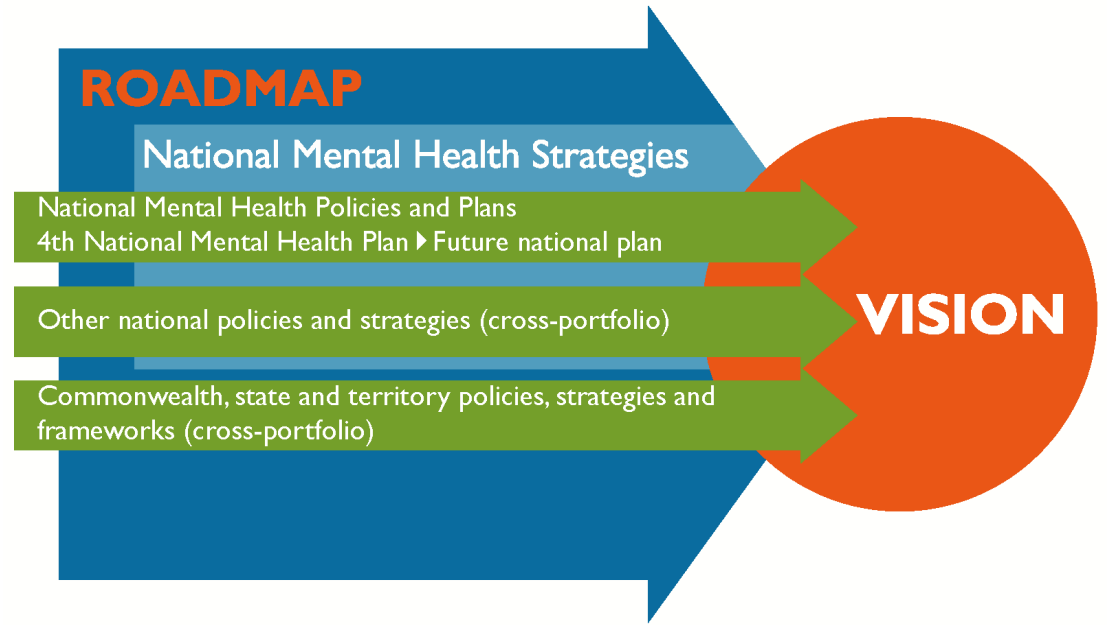

Figure 1. Road Map for National Mental Health Reform 2012-2022(COAG, 2012) 
The national strategy document (COAG, 2012) has identified some priorities areas to build up a robust resilience in promoting mental health needs of the Austrlian society:

Priority 1: Promote person-centred approaches.

Priority 2: Improve the mental health and social and emotional wellbeing of all Australians.

Priority 3: Prevent mental illness.

Priority 4: Focus on early detection and intervention.

Priority 5: Improve access to high quality services and supports.

Priority 6: Improve the social and economic participation of people with mental illness.

In context of the above strategy document, it is interesting to note that there is no terms of reference of medical model or pure psychiatric nomenclature excluding the psychosocial factors, rather the road map recognizes the value of diverse psycho-social components to restore natural resilience of clients in preventing or improving mental health needs of the people. It has talked about the roles of family, school, extended agencies and professionals in this discourse. Yip (2004) has completed study on community mental health services in Hong Kong and noticed how the psychosocial elements of client's wellbeing and protective factors can be compromised due to imbalance in the multi-disciplinary mental health system. He observed consistent undermining attitude of medical professionals, especially psychiatrist, regarding contribution of social workers in mental health system. The Beyondblue Depression Initiative, a major policy guidelines, has a very clear mandate that 4-6 psychotherapy sessions must be tried before starting pharmacological treatment (Beyondblue, 2011; Robotham, 2012). The guidelines have potential to reenergizes the CAMHS services.

\section{Current Methods of Interventions and Need for SBP}

The key concerns noted in the current methods of CAMHS assessment and intervention:

- Disease/diagnosis focus intervention. Bio-psychosocial element has been overshadowed by biomedical driven model(Pilgrim, 2002). For example, on a crisis case presentation, the admission of a teenage client had to be referred as psychiatric admission rather than social admission.

- Weakness focused rather than strength focused approach.

- Not enough focus on stabilizing the key settings and concerned parties (Parents, family, school, playground, support networks).

- Intervention is driven by diagnosis rather than symptom.

- Individualistic approach rather than whole system approach.

- Poor balance in multidisciplinary bio psychosocial system
- Intervention often do not have clear long term vision or clarity of focus.

- Leaderships and coordination issue.

- Values and ethical issue in practice. For example, in a Care Team Meeting (CTM) professionals are often noted trying to protect each other rather than advocating for the child and empowering parents.

- Resource issue. This is particularly felt in rural and remote context of Australia.

- Calmer class room is a national policy to integrate and empower the vulnerable children in the school through attachment and relationships focus support, but there are concerns regarding degree of its implementation.

- Lack of focus on key components of mental health like trauma, attachment and system rather than numerically based judgment focused intervention.

\section{Why SBP}

SBP is the response to deficit focused treatment approaches which are derived by biomedical model of treatment (Shooter, 2008; Santrock, 2007; Engel, 1977). There has been convincing evidence about the weakness of deficit focused intervention which only creates dependency and vulnerability in client through lack of control on their existing treatment process (khan and Miles, 2011). SBP is an alternative to deficit thinking and pathological approach in assessment and intervention of CAMHS (Laurensen, 2000). Goolishian(in Laurensen, 2000, p75) states:

The defiency language has created a world of description that understands only through what is wrong, broken, absent or insufficient. The deficiency language has created a world of mental health that can be compared to a balck hole out of which there is little hope to escape whether we are clinician, theoretician, or researcher.

Pulla(2012) described SBP as inherent strength of individuals, groups and community organisations that structure recovery and empowerment programme building on people's natural strengths. Pulla (2006) referred Gandhian values of fairness, respect and self-directed transformation as steppingstone to impact and influence individuals, groups and even political institutions in making progressive change. The example of Gandhi is self-evident. Under the great humanistic values Gandhi was able to inspire and connect with millions of Indian to stage peaceful sociopolitical movement to secure freedom from the British Raj. Pulla (2012 p. 52-53) gone further and raised the possibility of the freedom in our generic social and emotional wellbeing:

A Strengths based Approach allows people to identify and build on their strengths( Francis, 2012) so that they can reach their goals, and retain or regain independence in their daily lives.

The World Health Organisation defined mental health as a state of social and emotional wellbeing in which an 
individual understands his or her own abilities, can cope with the normal stresses of life, can work productively and is able to make a contribution to his or her community. In this positive sense, mental health is the foundation for individual well-being and the effective functioning of a community (WHO, 2013c).The definition draws on the individual's capacity building and self-reliance approach which is essentially strength focused. Laursen (2000) advocates to see the difficulties and struggles of the families as opportunities, hope and solutions rather than problem and hopelessness.

The SBP strives for a humanistic treatment approach which will be built on the existing strength of the children and families and their voice will be reflected in the professional decisions and interventions. In this process, professionals will remain as partner (rather than expert) and will focus on a treatment goal which will be long term rather than short term quick solution focused.

\section{How did We Use Strengths Based Practice in Our Work?}

SBP is a humanistic practice principle with following fundamental values and goals. It acknowledges client's inherent potentialities for change and self-reliance. SBP facilitates respectful, transparent and culturally appropriate practice to progress on client's pace. The strength perspectives also integrate a client's living experiences and professional's knowledge and skills including enhancing client's natural protective factors of mental health (i.e. attachment with parents, insight and control about illness and its management, positive socialization and social activities, support networks).

To demonstrate the implication of the above practice principles, the following case study has been imagined by the authors for the purpose of the paper:

Case Scenario: Johnny is a 10 years old boy living with his mother; younger sister aged 8, mother's partner and his 9 years old daughter from his previous relation. Johnny was referred to CAMHS for aggressive and disruptive behaviour at home and school. The school is concerned about Johnny's aggression towards students and teachers and its impact on his academic and social development. Johnny has a diagnosis of ADHD by a local pediatrician and currently on medication. In spite of several medical reviews, the pharmacological treatment seems making no difference to address his difficult behaviour. Once he threatened of killing his class teacher and bombed the school. The teacher was very upset and had to go on sick leave. He was suspended on several occasions. He is very isolated in the school as he struggles to keep friends due to his controlling behaviour. Johnny's parents have divorced three years ago. He loves to have contact with his father but this is not progressing well due to ongoing conflicting communication between parents. The role of father's current partner is also a cause for concern due to her discouraging attitude about Johnny's contact visit.
Johnny's behaviour has been causing significant stress in the family. In terms of developmental history, mother was subjected to a lot of domestic violence since prenatal stage and after birth, mother suffered from postnatal depression. Johnny was born as a healthy child, achieved his developmental mile stone age appropriately and he has always been an active child.

\section{Clinical Formulation}

Johnny's difficult behaviour has been predisposed by early developmental trauma via parental relationships difficulties, stress and anxiety, parental separation and loss and also, mother's post natal depression negatively impacted on his attachment development. Social stress at home and school have contributed as precipitating factors, which later graduated and perpetuated by social and emotional isolation at home and school that have caused anger, controlling tendency via negative attention seeking behaviour.

Assessment was organized by discussing with Johnny's family. On assessment, Johnny presented as a sociable, articulate young person who wants to have regular meeting with his father and wonders why nobody likes to play with him, which all influences his internal working model, self-image and potentialities reflect his potentialities for change. He has set out tasks for therapy and signed agreement to attend CAMHS service.

\section{Individual Work with Johnny}

Individual work was focused on creating safe therapeutic relationships and boundary through non-directive person centered approach by exploring his wishes and feelings. Therapy also focused on generating his awareness about his developmental experiences and its impact on his perceptual, cognitive, social and emotional development on his behaviour and social relationships. Individual therapy progressed in a creative spirit amidst different new ideas to empower Johnny by boosting his morale and self-esteem. Here is an innovative tool, "My Fleeing's Barometer" (Khan, 2014), used to help Johnny gain insight and natural control on his diverse emotions, sensations and behavioral presentations:

\section{My Feelings Barometer}

\section{Therapeutic Rationale}

My Feelings Barometer is a feelings and behaviour management systemic tool (created by the primary author), which was implemented with full participation of Johnny, carer and the therapist to recognize signs and symptoms of feelings and emotions understand the degree of behavioural consequences of feelings and emotions and develop strategies to manage them. Here is an account how the intervention progressed: 


\section{My Feelings Barometer}
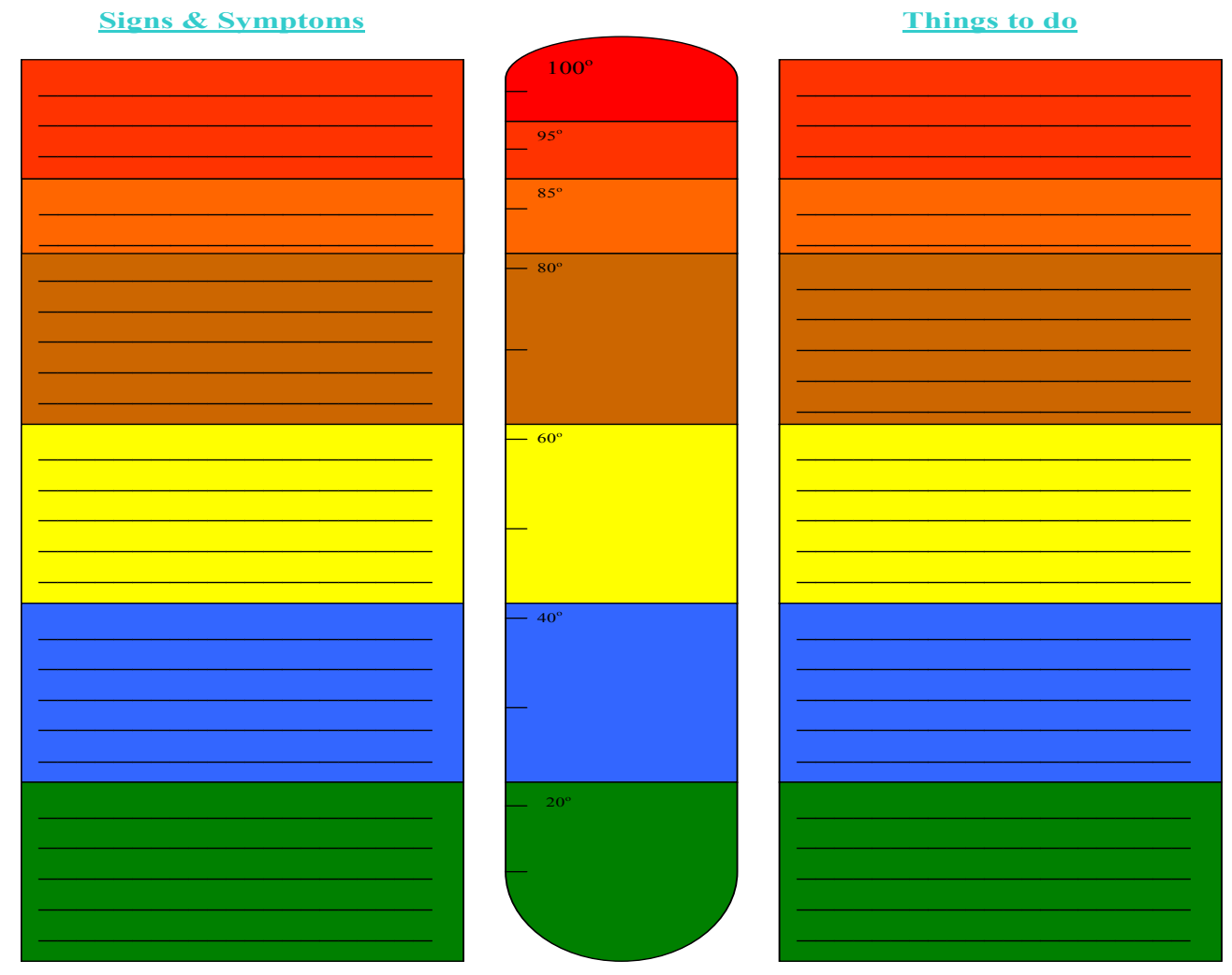

NAME:

Figure 2. 4 My Feelings Barometer (Khan, 2014)

\section{Descriptions}

The tool consists of degrees of stages of feelings and emotions and corresponding behavioural consequences which are identified through a symbolic barometer.

Johnny was supported to understand that the purpose of the activity was to understand and manage feelings and emotions in the right time before it escalates. The sessions progressed on Johnny and his family's pace to understand and integrate with the idea. Then he was supported to gain ownership of the document by inviting him to name the stages of the barometer by giving different names to each stage of feelings, and then identify the signs and symptoms of emotional and behavioural states followed by developing strategies to manage the symptoms sections. Initially, Johnny's was engaged in the process and then, with his permission, the parents joined in on the development of the strategies. Finally, with permission, a laminated copy was produced in order to monitor and manage his day-to-day difficult feelings and behaviour before it escalates. The process was regularly monitored in therapy with Johnny and his family which gradually helped Johnny to gain control on his emotions and behaviour. The positive outcome of the intervention is attributed to Johnny's understanding and sense of positive control on his emotional and behaviour and his parent's consistent encouragement for enforcement, sincerity and setting boundary. At times there were issues that Johnny was not disregarding or parents were losing motivation which were addressed in dyadic therapy with mother, and joint sessions with step dad. In terms of SBP, Johnny had the opportunity to build his natural resilience to manage his mental health needs.

\section{Dyadic therapy with mum to facilitate developmental attachment}

The idea of dyadic incorporates therapeutic work with child and a significant other (Hughes, 1997). The dyadic therapy was focused on exploring all aspects of Johnny's relationships, love; fun; conflict; discipline and difficulty to trust, were explored, discussed and reenacted (Hughes, 1997). The sessions progressed to repair the damages in the relationships and forming a sense of trust and emotional integration in the relationships. The process also involved dyadic therapy session, individual psych-education sessions with mum and step dad. This partnership intervention was 
critical to reactivate the natural protective factors at home via positive parenting support.

\section{Working with father to improvise quality of contact}

Contact was made with the biological father, his views, suggestions and grievances were explored, reframed before discussing with Johnny, mother and her partner to structure a suitable plan for communications to facilitate contact with father. This was monitored on regular basis. Positive outcome in Johnny's behaviour was noted after biological father was brought into the support network.

\section{Working with school}

Liaison with school was carefully planned in partnerships with teacher, principle and representative from the department of Education. The following collaborative plan was drawn with Johnny and the key stakeholders to create safe and supportive environment in school:

- Identification of early symptoms (i.e. showing non-cooperation, controlling behaviour, inviting trouble) and immediate action with emotionally attuned and calm approach. There should not be any sign of overreaction which will potentially escalate his behaviour.

- Respecting privacy: No teacher/staff should talk negatively or discuss about his difficult behaviour publicly or in front of other students.

- $\quad$ Protecting him from Bullying: Johnny will be very vulnerable to integrate into the school environment, students might try to stigmatise and exclude him or provoke to get him into trouble.

- $\quad$ Any presented difficult behaviour should be handled calmly and maturely on the spot in a generic way (in case of major escalation, separately), without any sign of exclusion.

- Suspension should not be used as tool for behaviour management; it inflicts sense of exclusion and humiliation and potential for more negative behaviour. In dire situation, instead of sending home, Johnny can be made to sit in the office to do work or engage in appropriate calming activities.

- Debriefing (5-10 minutes) before finishing school to alleviate chances of carrying stress home, and preparing him to return to school next day with positive motivation, rather than being anxious about school.

- Careful review and planning regarding his academic needs. If necessary, curriculum may be modified to facilitate positive school experience.

- $\quad$ Rapport building with a teacher/aid, as an investment, who Johnny can relate to in times of stress/anxiety due to sense of being in trouble or exclusion.

- Calmer classroom: To be mindful about the impact of his developmental trauma and attachment on his coping ability, social and emotional skills and ability to manage social communications and relationships.
The Victorian Government has a clear direction to support traumatised children in the school through appropriate understanding traumatised children and developing relationship based skills to help them(State of Victoria, 2007).

- Mentoring Programme: Consideration should be given in appointing a teaching staff to provide appropriate social and value education and role model ship. This will also focus on generating a dream about life with different short-term goals.

- Self-esteem building initiative: The school may develop creative approaches to boost up Johnny's self-esteem and confidence by facilitating participation in sports and extra-curricular activities, delegation of responsibilities (if it is safe for everybody) while monitoring performance and innovative school based projects. Every opportunity should be exploited in publicly commending his positive skills/performance (if any).

\section{Methods Employed}

Given SBP is a broader perspective; it can be located in a range of areas that facilitate creative space to support and empower the children and young people and their environment.

Person centered approach (PCA): PCA also known as client-centered therapy is based on the hypothesis regarding three different selves of a human being: self-concept, real self and ideal self and it aims to bring greater congruence among the selves of the client through unconditional positive regard and empathetic understanding (Holosko et al, 2008). The role of the therapist is just a partner, not a problem solver, who will treat client as human and establish a genuine and empathetic relationship to facilitate self-actualizations (positive self-esteem, self-worth and self-image) and freedom of choice. It creates empowering atmospheres, which allow children and young people to heal themselves through the experiences of positive social interaction (Axline, 1989). This approach helped Johnny to develop a sense of himself that became the foundation for change and hope.

Psychodynamic Approach: The theoretical idea of psychodynamic model consists of Erikson's bio psychosocial perspective on human behaviour, which suggests that individual growth and development occurs on lifelong basis, with each developmental stage building on another (Greene, 2008). Bio-psychosocial perspectives throw light in understanding mental illness in terms of children's living experiences in environment and its potential impact on their behaviour and relationships. Psychodynamic perspective helps us understand and interpret the impact of past and ongoing experiences of abuse, neglect and trauma of parents and children on their cognitive, perceptual and affective experiences and related behaviour (Hughes, 1997). For example, psychodynamic approach 
outlines a different meaning to the reason of Johnny's deregulated behavior being predisposed by his experiences of emotional abuse and developmental trauma since prenatal stage, followed by diverse perpetuating factors. The psychodynamic perspective not only meaningfully interpreted the reasons of the challenges but to develop a clinical formulation for treatment plan.

Systemic Approach: Systemic perspective has been derived from Erickson's person in environment theory and Hartman (1995)' Eco map concept that acknowledges the impact of wider physical and social environment (Greene, 2008) in children's developmental functioning. Mattaini (2008) has expressed concerns that the person in environment concept has been defined and redefined in the last century but the social work practitioners have switched sides in terms of their own preference and ignored either the person or the environment. This isolated practice approach has led them to often attempt to intervene with clients by amputating them from their environment and interactional realities. The isolated practice approach needs to be understood in the background of increasing dominations of medical model in the current system. In child and adolescent mental health, the environment consists of the significant key players like parents and family, school, health and social care systems and cultural development opportunities.

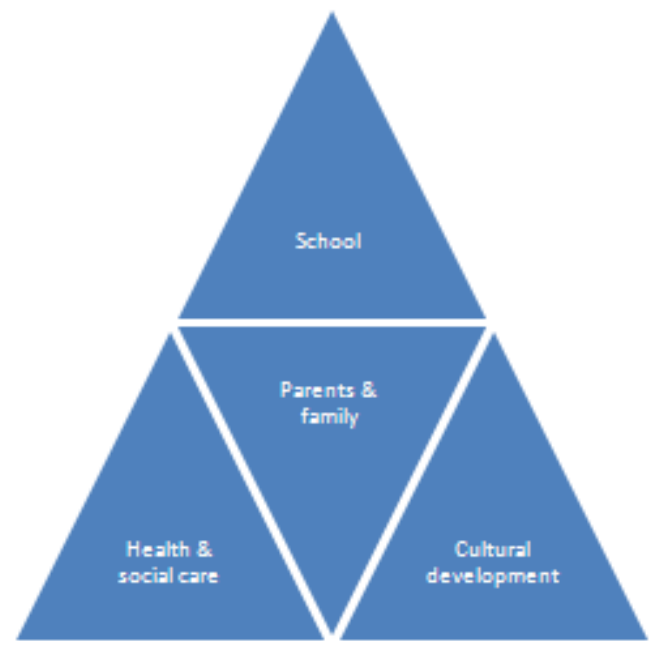

Figure 3. Systematic factors of child development \& well-being (Khan, 2014)

These factors are deeply integrated and interdependent. For example, if the child does not feel safe at home, he/she will struggle to engage in either school or in therapy. If the child has any medical, mental or developmental conditions he/she will be particularly vulnerable in absence of appropriate health and social care resources. The cultural perspective recognizes the importance of cultural connectedness and also culturally appropriate practice. Tseng's (1999) work identifies that practitioners, if not appropriately matured, can face cultural transference and countertransference in cross-cultural practice. Tseng (1999 p.161) outlines:
Cultural transference refers to a patient developing a certain relationship, feeling or attitude toward the therapist because of the therapist's ethno-cultural background; cultural countertransference implies the reverse phenomenon, namely, a therapist developing a certain relationship with the patient mainly because of the patient's ethno cultural background.

The theoretical perspectives have informed the author's persistent engagement in pursuing the ongoing work with Johnny, his family and school in order to create a support network needed for his recovery and wellbeing amidst positive family functioning.

\section{Learning from the Practice}

The paper encapsulates the authors' reflective practice experiences amidst theoretical and policy discourse regarding emerging challenges of dominance of medical model, and opportunities to build natural resilience in children and families through Strength based practice (SBP). The discussion outlines the value of working on a long-term goal to address the mental health needs of children rather than diagnosis based quick fix focused intervention. The key argument behind SBP is its scope to address the root cause rather than the symptoms. For example, Johnny's insecure attachment was contributing to his emotional disregulative behaviour, which was addressed through dyadic developmental attachment building work alongside the mother rather than solely relying on pharmacotherapy. The family work, to improve communication and coordination among family members, was organized to address the perpetuating factors of internal conflict, disappointment and anger via poor parental relationships and contact issue with father. It is critical to address the social and emotional environmental factors to find the prognosis for change. Pharmacotherapy is important, if needed, however, it should not be the sole option. If the key environmental issue is not addressed it will remain as a perpetrator which will not allow the internal emotional resources to build resilience. The bio psychosocial assessment concept is the acknowledgement regarding the importance of SBP to assess the issue comprehensively and address the major issue, environmental factors (i.e. home and school) associated with children and adolescent's mental health needs. However, in the wake of domination of medical model, the idea of bio psychosocial perspective seems weakened. The recent research completed by the University of Melbourne on a sample of 150 adolescents attending CAMHS service suggest that $75 \%$ of depressed adolescents were prescribed drugs before psychotherapy has been given a proper chance to work which is contradictory to national guidelines that four to six psychotherapy session must be offered before attempting pharmacological treatment (Robotham, 2012). The study revealed doctors systematically recorded the severity of the depression they diagnosed in only half of cases - even though this is considered essential for determining what type of 
therapy is likely to work best, and for assessing later how well the person is responding to it.

The other observation is, even though the technical term of SBP is popular in the western literary world but ironically it is facing challenges in its optimum utilization. In a different social context, SBP have been popular since time immemorial in the Asian continent under the realm of socio-cultural rhetoric, which have guided social values, positive life style, discipline, tolerance, compassion, value in small initiative and universal wellbeing. The Asian model of SBP teaches us that individual wellbeing is connected with the group or community wellbeing. It has advocated for community capacity building through resource mobilization in individual and group context. This brings the argument for a comprehensive approach of partnerships under person centered, psychodynamic and systemic perspective. Even though SBP has received a lot of attention in social policy(OHCHR, 1989), social science research, UN mandate, however, it is still not gaining a reasonable momentum in the western world due to CAMHS system's increasing reliance on medical model via patholising of children's behavioural and developmental symptoms. It has rather gained popularity in the south Asia with substantial contribution from Islam, Hinduism, Christ Buddhism including preaching of Gandhi, Tagore and Mother Teresa have made substantial impact in defining value based disciplined social life under whole community approach. The idea of yoga, mindfulness and even different religious healing programme have been in practice in managing and protecting mental health needs of children and the family members.

\section{Way Forward}

The starting point of inculcating SBP in CAMHS is to generate more awareness about its potential for optimum implementation of multidisciplinary bio-psychosocial approach. This multidisciplinary scientific approach promotes an evidence based specialist service has been an internationalized recommended treatment method (WHO, 2013). Even though, this has been adopted in most of the developed countries but in practice front, there have been issues about its quality of implementation due to increasing reliance on medical model, which is ultimately depriving the society from the benefit of the strength based modern treatment idea. The issue seems very complex and deep routed, so it needs careful measures on a number of fronts:

- Generating awareness among professionals about the strength base values of the bio-psychosocial system in equal representations of disciplines.

- Securing appropriate changes in the policy and legal fronts that are creating hindrance in optimum implementation of bio psychosocial system. For example, targeting the terms of references in bio-psychosocial system, in the mental health legislations as well as organization's policy documents contributing to the discrepancies.

- Structuring a formal mechanism to govern the system and monitor the issues in the optimum implementation of strength focused bio psychosocial approach.

- UNCRC (OHCHR, 1989) guidelines need to be commissioned in the mental health policy and reforms and implementation.

- Institutional culture and leadership needs to be convincingly committed for appropriate implementation of bio psychosocial model.

It is important to acknowledge the key stakeholder's challenge in gracefully claiming their professional space in the current climate of competitive multidisciplinary forum. However, this needs more debate and understanding whether the current imbalance is due to dominance of medical model or comparative competency issue of the non-medical partner professionals in the system. But, there is least doubt that the current CAMHS service needs a transparent and consistent policy in addressing the issues in the system in terms of fairness and equality, advocating, and celebrating the partnerships and contributions of the professionals irrespective of discipline origin.

In the midst of the challenging scenario, the authors attempted to study the impression of the medical partners (e.g. psychiatry) by looking at their priority themes in the international conferences. It is quite interesting to note the changing focus of the medical partner in recognizing the value of psychosocial factors in mental health. For example, the main theme of the recent 21st World Congress Social Psychiatry (WASP, 2013) was," The bio-psycho-social model: The future of psychiatry." In addition, interestingly, major topics chosen in the international conference have strongly reflected their recognition of social factors in mental health intervention:

1. Bio-psycho-social confluence of psychiatric sciences

2. Life-span perspectives of mental health

3. Natural Disasters/Man-made (including Fukushima) and mental health

4. Co-morbid mental and physical illnesses

5. Globalization, instant communication and mental health

6. Mass movements of populations: migrants, refugees and others

7. Suicide and its prevention

8. Stigma of mental disorders and psychiatric institutions

9. Creating alliances to respond to mental health challenges (WASP, 2013).

In its newly formed website to commemorate the 50 years of existence of social psychiatry, professor Moussaioui, the chairman of the World Association of Social Psychiatry, even acknowledged the contribution of spiritual healers in some parts of the world and strongly pledge that mental health intervention must anchor bio-psychosocial treatment framework with special emphasis on social and cultural diversity of the people (Moussaioui, 2013). The changing focus of psychiatry clearly acknowledge the need for new approach, away from pathogenic and diagnostic route, 
essentially by focusing on the inherent strength of people through SBP.

\section{Conclusions}

SBP has not only created wider space in the service system but a modern answer to ten and thousands of children suffering from mental illness in global context. However, the key argument for SBP is its strong scientific base and wider recognition to promote long-term recovery and wellbeing without risking children by over medication with short-term goal attainment approach. SBP, extracted from bio-psychosocial perspective is a scientifically derived global idea, which was carefully introduced in the CAMHS system internationally for rebuilding human resilience by empowering clients with realistic insight, control on recovery \& wellbeing and capacity for self-care and protection. The bio-psychosocial practice approach is a SBP principle that strives to enhance people's capacity for a progressive change. However, in the practical front, the idea is not getting reasonable opportunity to demonstrate its credibility due to increasing domination of medical model through diagnosis and leveling limitation as well as creating imbalance in the multidisciplinary system. Because of the imbalance in the system, the benefit of the SBP approach of bio psychosocial model is not being appropriately realized, frequent representations of children in the system is a potential indicator of the gap in the service.

Finally, Children's mental health does matter, as they are future men and women of the society. However, due to lack of appropriate harmony in the multidisciplinary system, the CAMHS seems struggling to deliver the expected result and increasing vulnerability among many children (Harpaz-Rotem et al, 2004, Wang (2007). It is high time to fix the problem before it is too late. The situation demand political will and collective response to uphold the values of a SBP in the CAMHS system.

\section{REFERENCES}

Australian Institute of Health and Welfare (2013). Mental Health. Australian Institute of Health and Welfare. [Online] Available from: http://www.aihw.gov.au/mental-health/. Accessed on October 2013

Axline, V. (1989). Play Therapy, Ballantine Books, London.

Beyond Blue (2011). ANTIDEPRESSANTS FOR THE TREATMENT OF DEPRESSION IN ADOLESCENTS AND YOUNG ADULT. [Online] Available from: https://www.bspg.com.au/dam/bsg/product?client=BEYONDBLU E\&prodid $=$ BL/0474\&type $=$ file Accessed on October 2013

Beyond Blue (2013). Beyond blue encourages young people to be active. Be happy. Be you. Beyond Blue. [Online] Available from: http://www.beyondblue.org.au/media/media-releases/media-releas es/-beyondblue-encourages-young-people-to-be-active.-be-happy.be-you- Accessed on October 2013
Burns, B.J., Costello E.J., Angold A., (1995). Children's mental health service use across service sectors. Health Affairs, V. 14(3) p $147-159$

COAG (2012). The Roadmap for National Mental Health Reform 2012-2022. Federal Australian Government. [Online] Available from:

http://www.COAG.gov.au/sites/default/files/The\%20Roadmap\%2 0for $\% 20$ National $\% 20$ Mental $\% 20$ Health\%20Reform $\% 202012-202$ 2.pdf.pdf. Accessed on August 2013

COAG (2007). The Roadmap for National Mental Health Reform 2012-2022. COAG. Canbera

Engel, G. L. (1977). The need for a new medical model: A challenge for biomedicine. Scienc., Vol.196, pp.129-136.

Francis, A. (2012). Journey towards recovery in mental health. In V. Pulla, L. Chenoweth, A. Francis \& S. Bakaj (Eds.), Papers in Strengths Based Practice (pp. 19-33). Delhi: Allied Publishers.

Goolishian, L. (1991). The Disengaging of Mental Health. In Laursen, E., Strength Based Practice with Children in Trouble. Reclaiming Children and Youth. Vol. 9:2, PP 70-75

Greene, R. (2008). Psychosocial Theory. In Thyer, B A; Showers, K M; Dulmus, C N(Eds.) Comprehensive Hand Book of Social Work and Social Welfare: Human Behaviour In The Social Enviornemnt. J Wiley, NJ

Harpaz-Rotem, I.; Leslie, D. And Rosenbeck, R. (2004). Treatment Retention Among Children Entering a New Episode of Mental Health Care. [Online] Available from: http://ps.psychiatryonline.org, Vol. 55- 9. Accessed on July, 2013

Hartman, A. (1995). Diagrammatic assessment of family relationships. Families in Society. In Kennedy, V. Eco maps. [Online] Available from: http://review.mai.ac.nz. Accessed on June 2013

Holosko, M; Skinner, J and Robinston, R. (2008). Person Centered Theory. In B. Thyer, K. Sowers, \& C. Dulmus, C. (Eds), Comprehensive Hand Book of Social Work and Soicial Welfare: Human Behaviour in the Social Enviornment. J Wiley, NJ.

Hughes, D. (1997). Facilitating Developmental Attachment: The Road to Emotional Recovery and Behaviour Change in Foster and Adopted Children. Jason Aronson, NJ

Khan, A. (2014). Engaging children with mental illness: A review of some empowerment based therapeutic approaches for Practice. In Francis, A. (Eds.) Social Work Practice in Mental Health, Sage, New Delhi.

Khan, A. \& Miles, D. (2011). Talk to Me, Not my Illness: Relevance of Human Rights and Social Justice in Child and Adolescent Mental Health Intervention. In Jones, P.; Miles, D.; Francis, A \& Rajeev, S.P. (Eds.), Eco-social Justice: Issues, Challenges and Ways Forwards. Book For Change, Bangalore.

Laursen, E. (2000). Strength Based Practice with Children in Trouble. Reclaiming Children and Youth. Vol. 9:2, PP 70-75

Lavis, P. (2008). Child and adolescent mental health service structures and policy. In, C. Jackson, K. Hill \& P. Lavis (Eds.), Child and Adolescent Mental Health Today: A Handbook', Pavilion, Brighton, UK.

Green, J.F.; McLaughlin, K.M.; Alegria, M.; Costello, J. E.; Gruber, M.J.; Hoagwood, H.W.; Leaf, J.P.; Olin, O.; Sampson, N. A.; Ronald, B.A. \& Kessler, C. (1996). Mental health service use in the 
community and schools: results from the four-community MECA study: methods for the epidemiology of child and adolescent mental disorders study. Journal of the American Academy of Child and Adolescent Psychiatry, Vol. 35 pp-889-897

Mattaini, M. A. (2008). Ecosystem Theory. In Thyer, B A; Showers, K M; Dulmus, C N (Eds.) Comprehensive Hand Book of Social Work and Social Welfare: Human Behaviour. The Social Enviornemnt. J Wiley, NJ

Moussaoui, D. (2013). World Association of Psychiatry: Opening message. World Association of Psychiatry. [Online] Available from : http://www.waspsocialpsychiatry.com/ Accessed on August 2013

OHCHR (2007). Convention on the Rights of the Child. High Commission for Human Rights, Geneva, viewed on 19 September 2011, http://www2.ohchr.org/english/law/crc.htm>

Oruche, U. M., Downs, S., Holloway, E., Draucker, C., \& Aalsma, M. (2014). Barriers and facilitators to treatment participation by adolescents in a community mental health clinic. Journal of psychiatric and mental health nursing. Volume 21, Issue 3, 241-248

Pilgrim, D. (2002). The bio- psychosocial model in Anglo-American psychiatry: Past, present and future. Journal of Mental Health, Volume 11, Issue 6, pp.585-594.

Pulla, V.(2012). What are Strengths based Practice all about? In Pulla, V., Chenoweth, L., Francis, A., Bakaj, S. eds .,(2012). Papers in Strengths Based Practice, New Delhi: Allied Publishers ISBN 978-81-8424-810-4

Pulla, V. (2006). Strengths Based Strategies, 2006, Editors Pulla, V. and Montgomery, Strengths based Strategies, resileicne as opposed to defiecits: working with stnrengths, , Brisbane Institute of Strengths Based Practice, Australia

Robotham, J. (2012). Drugs, not therapy, the first line of treatment for troubled adolescents. The Sydney Morning Herald. [Online]. Available from: http://www.smh.com.au/national/health/drugs-not -therapy-the-first-line-of-treatment-for-troubled-adolescents-2012 0708-21 pi3.html\#ixzz2aPnwCls9. Accessed on July 2013

Santrock, J. W. (2007). A Topical Approach to Human Life-span Development. (3rd ed.), McGraw-Hill, St. Louis, MO.

Sayal, K. (2008). Attention deficit/hyperactivity disorder. In C. Jackson, K. Hill \& P. Lavis (Eds.), Child and Adolescent Mental Health Today: A Handbook, Pavilion, Brighton, UK.

Shooter, M. (2008). What is mental health?. In C. Jackson, K. Hill
\& P. Lavis (Eds.), Child and Adolescent Mental Health Today: A Handbook, Pavilion, Brighton, UK.

State of Victoria (2007). Calmer classrooms: A guide to working with traumatised children. The Office of Children's Commissioner. [Online] Available from:

http://www.ccyp.vic.gov.au/childsafetycommissioner/downloads/c almer_classrooms.pdf Accessed on June 2013

Tseng, W.-S. (1999). Culture and Psychotherapy: Review and Practical Guidelines. Transcultural Psychiatry. Vol.2, pp.131-179. Sage.

Wang, J. (2007). Mental health treatment dropout and its correlates in a general population sample. Med Care. Vol.45(3) pp 224-9.

WASP (2013). Main Topics. 21st World Congress on Social Psychiatry. [Online] Available from :

http://www.wasp2013.com/topics.html. Accessed on August, 2013

WHO (2013). Child and Adolescent Mental Health. World Health Organisation. World Health Organisation [Online] Available from: http://www.who.int/mental health/prevention/childado/en/.

Accessed on July 2013

WHO (2013). Mental health: strengthening our response. World Health Organisation. [Online] Available from: http://www.who.int/mediacentre/factsheets/fs220/en/index.html. Accessed on July 2013

WHO, (2013a). WHO gives countries tools to help stop abuse of people with mental health Conditions. World Health Organisation. [Online] Available from:

http://www.who.int/mediacentre/news/notes/2012/mental_health 20120615/en/index.html

Yip, K. S. (2004). Medicalization of Social Workers in Mental Health Services in Hong Kong. British Journal of Social Work, Vol. 34 PP- 413-435

Australian Bureau of Statistics (2013). Mental health and wellbeing in Australia has progressed over the last decade. Government of Australia. [On line]. Available from:

http://www.abs.gov.au/ausstats/abs@.nsf/Lookup/1370.0main+fea tures252013 Accessed on April, 2014

State of Victoria (2006). CAMHS in communities Working together to provide mental health care for Victoria's children and young people. Department of Human Services Melbourne, Victoria. [Online] Accessed from: http://www.health.vic.gov.au/mentalhealt h/camhs/camhsrep0906.pdf Available on March 2014 